\title{
Unexplained variability of glycated haemoglobin in non-diabetic subjects not related to glycaemia
}

\author{
J.S. Yudkin ${ }^{1}$, R.D.Forrest ${ }^{4}$, C. A. Jackson ${ }^{1}$, A. J. Ryle ${ }^{2}$, S. Davie ${ }^{3}$ and B. J. Gould ${ }^{3}$ \\ Academic Unit of Diabetes and Endocrinology, Department of Medicine, University College and Middlesex School of Medicine, \\ Whittington Hospital, ${ }^{2}$ Department of Nutrition and Dietetics, Whittington Hospital, London, ${ }^{3}$ Department of Biochemistry, \\ University of Surrey, Guildford, UK, and ${ }^{4}$ Department of Clinical Chemistry, Centrallasarettet, Boden, Sweden
}

\begin{abstract}
Summary. We have studied levels of glycated haemoglobin in a sample of 223 people aged over 40 years without known diabetes mellitus screened in a community study. Each had a glucose tolerance test and glycated haemoglobin measured by four methods - agar gel electrophoresis with and without removal of Schiff base, affinity chromatography and isoelectric focusing. The correlation coefficients between $2 \mathrm{~h}$ blood glucose and levels of glycated haemoglobin were between 0.43 and 0.64 . This poor correlation was not explained on the basis of assay or biological variability of either $2 \mathrm{~h}$ blood glucose or glycated haemoglobin. Multiple regression analysis showed that other assays of glycated haemoglobin contributed to the variance of any single glycated haemoglobin value by $0.1 \%-52.9 \%$ (median $12.8 \%$ ) compared to the variance of $18.6 \%-41.4 \%$ (median $30.8 \%$ ) explained by $2 \mathrm{~h}$ blood glucose alone, suggesting that in a non-diabetic population, the degree of glucose intolerance may explain only one third of the variance of glycated haemoglobin levels, but
\end{abstract}

other factors operate to produce consistent changes in levels of glycated haemoglobin. Investigation of 42 subjects with consistently high ( 20 subjects) or low ( 22 subjects) levels of glycated haemoglobin relative to their $2 \mathrm{~h}$ blood glucose level showed no difference in age, gender, body mass index, haemoglobin levels or smoking, although $50 \%$ of low glycators had impaired glucose tolerance. Neither ambient bloodglucose levels, as estimated on two five-point blood-glucose profiles, nor dietary intake of carbohydrate, starch, sugars, fibre or alcohol, explained the difference between high and low glycators. The determinants of the consistent interindividual differences in levels of glycated haemoglobin in nondiabetic subjects remain to be determined.

Key words: Glycated haemoglobin, glucose intolerance, ambient blood-glucose levels, dietary carbohydrate, dietary fibre.
Levels of glycated haemoglobin are used to assess metabolic control in diabetic patients. Other proteins besides haemoglobin undergo glycation, and this process has been implicated in the development of diabetic complications [1]. It has been suggested that advanced glycation end-products, formed by a condensation of glycated proteins, may account for both normal ageing and the more rapid degeneration of tissues seen in diabetes $[2,3]$.

In diabetic patients, glycated haemoglobin levels correlate with mean concentrations of blood-glucose [4], and correlation coefficients as high as 0.98 have been reported between glycated haemoglobin and mean bloodglucose levels [5]. In subjects without known diabetes, the correlation between glycated haemoglobin and fasting blood-glucose (FBG) levels or blood-glucose levels $2 \mathrm{~h}$ after a glucose load $(2 \mathrm{hBG})$ is much lower [6-9]. This is partly because both assay and biological variability may make a larger contribution to the variation at low levels of glycated haemoglobin, and over the narrow range seen in non-diabetic subjects. However, this has not been studied systematically.
In the Islington Diabetes Survey [10-12] a sample of 223 subjects had two glucose tolerance tests, and estimates of glycated haemoglobin on two occasions, on the second of which the assay was performed by four different methods on both the fasting and $2 \mathrm{~h}$ blood samples [1214]. Wide differences in levels of glycated haemoglobin relative to the degree of glucose intolerance were found in this population, but levels of glycated haemoglobin were more closely interrelated, even when analysed by methods relying on different physicochemical properties. In this report we study the relationship between FBG, $2 \mathrm{~h}$ blood glucose, and glycated haemoglobin by the four methods, we analyse the contribution of assay and glucose tolerance test variability to the low level of correlation of these measures, and investigate the interrelationship between different assays of glycated haemoglobin. We also report on studies of subjects selected on the basis of consistently high and low levels of glycated haemoglobin relative to their-degree of glucose intolerance, to determine whether differences in ambient blood-glucose profiles or in diet might explain differences in levels of glycated haemoglobin relative to the degree of glycaemia. 


\section{Subjects and methods}

\section{The Islington Diabetes Survey}

The Islington Diabetes Survey has been described previously [10-12]. In this 2-phase community-based study, a random sample of 1,084 non-diabetic subjects over the age of 40 was examined in phase I; this comprised an abbreviated $75 \mathrm{~g}$ oral glucose tolerance test (OGTT), with estimation of blood-glucose ( $2 \mathrm{hBG}$ ) and glycated haemoglobin on a fingerprick blood sample $2 \mathrm{~h}$ after the glucose load. In phase II, a stratified sample of 223 of the phase I subjects, biased towards those with more marked degrees of glucose intolerance [10-12], was re-examined. A full $2 \mathrm{~h}$ OGTT was performed using venous samples, and assay of glycated haemoglobin was performed by four methods on the fasting and $2 \mathrm{~h}$ samples. Different assay results were available for between 156 and 216 subjects, with 136 subjects having data available for all variables.

\section{Characterisation of high glycators and low glycators}

Subjects were classified according to their mean levels of $2 \mathrm{hBG}$ and of glycated haemoglobin. In order to obviate the problem posed by the differences in ranges for the different assays, the subjects were classed into centile rankings of $2 \mathrm{hBG}$ at screening and at recall, and of glycated haemoglobin at screening and by each assay method both fasting and $2 \mathrm{~h}$ post-glucose at recall, and the mean centile $2 \mathrm{hBG}$ and mean glycated haemoglobin centile were calculated. To avoid possible misclassifications, any subject whose ranking differed by more than 50 centiles between screening and recall was excluded ( 13 subjects for $2 \mathrm{hBG}$ and 6 subjects for glycated haemoglobin), as were those with only one value of $2 \mathrm{hBG}$ ( 17 subjects), and those for whom the standard deviation of the mean centile ranking of glycated haemoglobin exceeded 30 centiles ( 4 subjects). There were 42 subjects in whom mean $2 \mathrm{hBG}$ ranking differed by at least 30 centiles from their mean ranking for glycated haemoglobin. All of these subjects were invited to participate in the next two parts of the study.

\section{Dietary survey}

Twenty-five subjects ( $60 \%$ of those eligible) satisfactorily completed this part of the study, which was conducted approximately $2.3 \pm 0.2$ years after the original screening study. Each subject recorded a 7-day food diary, and was visited at home by a dietitian for a complete diet history, backed by a cross-check of consumption frequency of a number of relevant foods [15], and using household measures, food models and photographs to assess portion sizes. All dietary histories were taken within a two month period. The daily intake of all nutrients was calculated from standard food tables [16-19]. Carbohydrate intake was expressed as total carbohydrate, sugars, and "glucose equivalents", the latter representing the glucose residues in starches and dextrins, in lactose, sucrose and maltose, as well as free glucose [17]. Soluble and insoluble dietary fibre were separately calculated $[18,19]$.

\section{Measurement of ambient blood-glucose}

Sixteen subjects ( $38 \%$ of all those eligible) participated in this part of the study which took place $4.4 \pm 0.2$ years after the original screening study. Because of the problems associated with home blood-glucose monitoring in elderly subjects, this was performed in a hospital setting. Subjects attended the Clinical Investigation Ward at the Whittington Hospital at 08.30 hours after an overnight fast and were encouraged to follow their usual level of activity. A 5-point blood- glucose concentration curve was taken, employing fingerprick blood samples, at $09.00,10.30,12.00,13.30$ and 14.30 hours, representing the fasting, $1 \mathrm{~h}$ post-breakfast, pre-lunch, $1 \mathrm{~h}$ post lunch and $2 \mathrm{~h}$ postlunch blood-glucose concentrations respectively. Studies on diurnal blood-glucose profiles in both non-diabetic and diabetic subjects have demonstrated good correlation between both fasting and postprandial blood-glucose levels and $24 \mathrm{~h}$ mean levels $[20,21]$ as well as good reproducibility on different days $[20,22]$. Each subject was offered a range of food for breakfast and for lunch, and selected the items which would most closely represent their usual meals. The profile was repeated on a second day during the subsequent four weeks in 14 of these subjects. Fingertip blood samples were collected onto filter paper impregnated with boric acid [23] (see assay methods). Because of the interval between the different phases of the study 13 subjects $(31 \%)$ had a repeat estimation of glycated haemoglobin levels by all four assays during this part of the study in order to test the stability of the assays over this period.

\section{Assay methods}

Because the screening survey was performed with the use of fingerprick capillary blood samples, whole blood glucose was assayed in both phases of the study and not plasma glucose. Blood-glucose was measured by a glucose oxidase method (Technicon I, Technicon Industrial Co, Basingstoke, Hampshire, UK). The blood samples during the study of ambient blood-glucose concentration were collected onto boric acid-impregnated filter paper [23], and the spots were eluted into $2.5 \%$ trichloroacetic acid and estimated using a glucose oxidase method on a Cobas Bio Centrifugal Analyser (Roche Ltd., Welwyn Garden City, Hertfordshire, UK). In phase I of the study, glycated haemoglobin was measured by agar gel electrophoresis (Corning Medical Ltd, Halstead, Essex, UK) without prior removal of the labile Schiff base (total GHb-screening) [24]. In phase II, glycated haemoglobin was assayed by four methods - agar gel electrophoresis without removal of Schiff base (total GHb-recall) [24], agar gel electrophoresis with prior removal of Schiff base by incubation with dipotassium phthalate (stable $\mathrm{GHb}$ ) [25], isolectric focusing (LKB, Bromma, Sweden) [26] and affinity chromatography on boronate gel (Glycogel B, Pierce and Warriner, Chester, Cheshire, UK) [27]. The first three of these assays were performed within $48 \mathrm{~h}$ of sampling at the Whittington Hospital, while the samples for affinity chromatography were transported to the Department of Biochemistry, University of Surrey, and assayed within seven days. Our own observations confirm the previous finding [28] that levels of glycated haemoglobin are stable over this period of time. The withinand between-assay coefficients of variation of thesc assays on ten replicate samples have been reported [14]. Haemoglobin levels were measured colorimetrically on an EDTA sample using a Coulter haemoglobinometer (Coulter Electronics Ltd., Luton, Bedfordshire, UK) [29]. Diabetes mellitus and impaired glucose tolerance were defined according to World Health Organisation (WHO) criteria $[30]$.

\section{Statistical analysis}

Linear and multiple regression analysis using raw data, and Pearson's correlation coefficient have been employed to express the relationship between levels of $2 \mathrm{hBG}$ and of glycated haemoglobin, as, despite the moderately skewed nature of the data, logarithmic transformation has little effect on the strength of the relationships reported. All multiple regression analyses were performed only on the 136 subjects for whom all values were available. Groups were compared using chi-squared analysis for proportions, and Student's $t$-tests or Mann Whitney U-tests for parametrically distributed and skewed continuous variables respectively. Unless otherwise stated, values are presented as mean $\pm \mathrm{SD}$. 


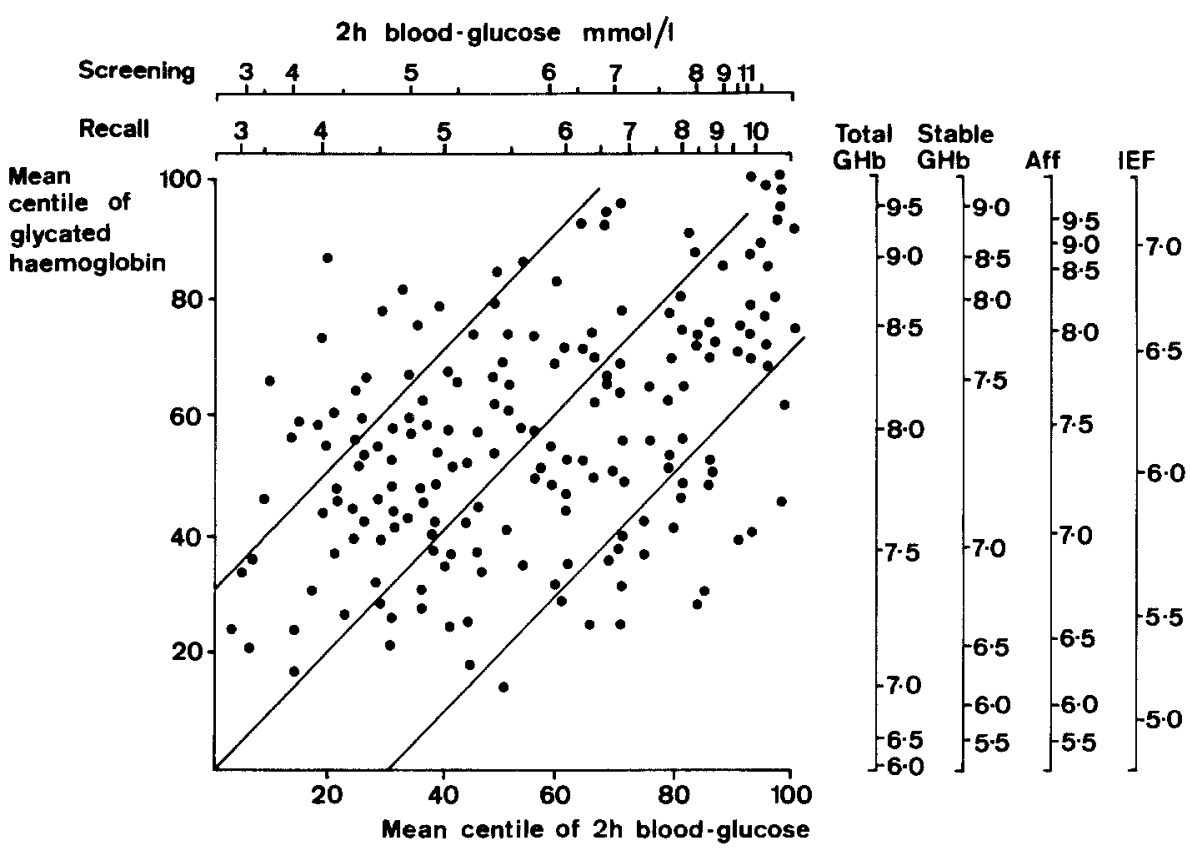

Fig. 1. Mean centile rankings of $2 \mathrm{~h}$ blood-glucose and of all assays of glycated haemoglobin at screening and recall. The lines of agreement and of +30 and -30 centiles are indicated, defining subjects with high and low levels of glycated haemoglobin respectively. The corresponding levels of screening and recall $2 \mathrm{~h}$ blood-glucose, and of $2 \mathrm{~h}$ post-glucose assays of glycated haemoglobin are indicated. Total glycated haemoglobin (GHb) - agar gel electrophoresis without removal of Schiff base; Stable glycated haemoglobin (GHb) - agar gel electrophoresis with prior removal of Schiff base; Aff affinity chromatography; IEF isoelectric focusing

\section{Results}

Correlation of glycated haemoglobin assays with $2 \mathrm{~h}$ blood glucose levels

In the screening phase of the study, the correlation between $2 \mathrm{hBG}$ and total $\mathrm{GHb}$-Screening was $r=0.51$ $(n=1031)$, this relationship being similar when analysed only for those subjects attending for recall $(r=0.49$, $n=217$ ). At recall, the relationship between $2 \mathrm{hBG}$ and total $\mathrm{GHb}$-recall on the $2 \mathrm{~h}$ post-load blood sample was very similar $(r=0.50, n=212)$. The correlation coefficients between $2 \mathrm{hBG}$ at recall and different assays of glycated haemoglobin were between 0.43 and 0.64 , with that of $2 \mathrm{hBG}$ with affinity chromatography being the strongest and with isoelectric focusing the weakest. The relationships of $2 \mathrm{hBG}$ with fasting and with $2 \mathrm{~h}$ post-load levels of glycated haemoglobin were similar.

In order to assess the contribution of glucose tolerance test variability, and of both assay and biological variability of glycated haemoglobin, to the weakness of the relationship between these variables, the mean level of $2 \mathrm{hBG}$ between screening and recall, and the mean level of total $\mathrm{GHb}$ between screening and recall, were employed. The correlation coefficient for this relationship increased to only $0.56(n=197)$, suggesting that such variability is not the major explanation for the weak relationship.

Multiple regression analysis was used to study the degree to which subjects with high or low levels of glycated haemoglobin by one method showed similar levels by other methods. In these analyses one level of glycated haemoglobin was treated as the dependent variable, and the contribution of $2 \mathrm{hBG}$ to its variance was assessed. Using multiple regression analysis, a different assay of glycated haemoglobin was added to the equation to assess the additional contribution of this second assay to the variance of the first while controlling for $2 \mathrm{hBG}$. The proportion of variance of glycated haemoglobin which was ex- plained increased from values of $18.6 \%-41.4 \%$ (median $30.8 \%$ ) for $2 \mathrm{hBG}$ alone, by an additional $0.1 \%-52.9 \%$ (median 12.8\%) for the combination of $2 \mathrm{hBG}$ and another assay. The additional variance explained was greatest between two assays of similar type (such as total and stable GHb), but methods employing different physicochemical properties contributed an additional $0.1 \%-16.1 \%$ (median $7.5 \%$ ) to the variance explained by $2 \mathrm{hBG}$ alone. These results imply that subjects with a high or low level of glycated haemoglobin by one assay method tend to have similar levels by all other methods, independent of the degree of glucose intolerance.

In order to determine whether the weakness of the relationship between indices of glycaemia and glycated haemoglobin levels is the result of employing the $2 \mathrm{hBG}$ level, a similar analysis was performed employing FBG levels instead. Fasting blood-glucose alone explained between $25.6 \%$ and $47.8 \%$ (median $36.6 \%$ ) of the variance of different glycated haemoglobin assays, while the additional proportion explained by other assays was $0.1 \%-41.3 \%$ (median $7.9 \%$ ), and by physicochemically different methods $0.1-11.6 \%$ (median $4.9 \%$ ).

\section{Characteristics of high and low glycators}

All subjects examined at recall were sorted into mean centile ranking of $2 \mathrm{hBG}$ and of glycated haemoglobin, and the relationship is shown in Figure 1. High and low glycators were classified as those whose mean $2 \mathrm{hBG}$ differed by at least 30 centiles from their mean ranking of glycated haemoglobin. There were 42 such subjects, of whom 20 had a mean ranking for glycated haemoglobin exceeding 30 centiles higher ("high glycators"), and 22 had a mean glycated haemoglobin ranking more than 30 centiles lower than for $2 \mathrm{hBG}$ ("low glycators"). One low glycator $(5 \%)$ had diabetes mellitus and $11(50 \%)$ had impaired glucose tolerance. There was no difference in age, gender, 
Table 1. Characteristics of low and high glycators

\begin{tabular}{|c|c|c|c|}
\hline & $\begin{array}{l}\text { Low glycators } \\
(n=22)\end{array}$ & $\begin{array}{l}\text { High glycators } \\
(n=20)\end{array}$ & $\begin{array}{l}\text { Significance } \\
\text { of difference } \\
\text { (p) }\end{array}$ \\
\hline Sex (male:female) & $8: 14$ & $6: 14$ & $0.91\left(\chi^{2}=0.01,1 \mathrm{df}.\right)$ \\
\hline Age (years) & $65.9 \pm 14.2$ & $59.8 \pm 9.3$ & 0.11 \\
\hline Body mass index $\left(\mathrm{kg} / \mathrm{m}^{2}\right)$ & $26.6 \pm 5.1$ & $27.8 \pm 4.3$ & 0.43 \\
\hline Haemoglobin $(\mathrm{g} / \mathrm{dl})$ & $13.9 \pm 1.4$ & $13.4 \pm 1.3$ & 0.23 \\
\hline $\begin{array}{l}\text { Smokers } \\
\quad \text { Cigarettes/day }\end{array}$ & $\begin{array}{l}4 \\
0-20\end{array}$ & $\begin{array}{l}9 \\
0-30\end{array}$ & $\begin{array}{l}0.06\left(\chi^{2}=3.52,1 \mathrm{df} .\right) \\
0.06\end{array}$ \\
\hline $\begin{array}{l}\text { Alcohol intake } \\
\text { (g/day, median (range) })\end{array}$ & $0.7(0-40)$ & $0.6(0-57)$ & 0.67 \\
\hline \multicolumn{4}{|l|}{ Differences in centile rankings } \\
\hline $\begin{array}{l}\text { - Mean glycated haemoglobin and mean } 2 \mathrm{~h} \\
\text { blood-glucose centiles (median (range)) }\end{array}$ & $-39(-57,-30)$ & $+40(+30,+67)$ & $t=28.96,40 \mathrm{df}, p<0.001$ \\
\hline $\begin{array}{l}\text { - Mean glycated haemoglobin and fasting } \\
\text { blood-glucose centiles (median (range)) }\end{array}$ & $-12(-46,+36)$ & $+36(-13,+63)$ & $t=5.96,40 \mathrm{df}, p<0.001$ \\
\hline
\end{tabular}

Values are shown as mean \pm SD except where indicated. The significance of differences is tested using Student's $t$-test for normally distributed data, by Mann Whitney U-test for skewed data, and $\chi^{2}$ for proportions

Table 2. Characteristics of low and high glycators participating in blood-glucose profiles

\begin{tabular}{llll}
\hline & $\begin{array}{l}\text { Low glycators } \\
(n=7)\end{array}$ & $\begin{array}{l}\text { High glycators } \\
(n=9)\end{array}$ & $\begin{array}{l}\text { Significance } \\
\text { of difference } \\
(p)\end{array}$ \\
\hline Sex (Male:female) & $2: 5$ & $2: 7$ & 1.00 \\
Age (years) & $64.3 \pm 12.6$ & $57.7 \pm 8.9$ & 0.24 \\
Body mass index $\left(\mathrm{kg} / \mathrm{m}^{2}\right)$ & $24.9 \pm 3.2$ & $27.1 \pm 5.1$ & 0.36 \\
$\begin{array}{l}\text { Differences in centile rankings } \\
\text { - Mean glycated haemoglobin and mean } 2 \mathrm{~h}\end{array}$ & $-40(-57,-30)$ & $+39(+30,+56)$ & $t=18.03,14 \mathrm{df}, p<0.001$ \\
$\begin{array}{l}\text { blood-glucose centiles (median (range)) } \\
\text { - Mean glycated haemoglobin and mean } \\
\text { profile blood-glucose centiles (median (range)) }\end{array}$ & $-47(-70,-32)$ & $+36(+3,+73)$ & $t=8.53,14 \mathrm{df}, p<0.001$
\end{tabular}

Values are shown as mean \pm SD except where indicated. The significance of differences is tested using Student's $t$-test and $\chi^{2}$

body mass index or haemoglobin level between high and low glycators $(p>0.1)$ (Table 1$)$. Nine of the high glycators $(45 \%)$ and four of the low glycators $(18 \%)$ were cigarette smokers $\left(\chi^{2}=3.5, p=0.06\right)$. No subject was taking regular salicylates.

When the high and low glycators were classed into rankings of FBG, there was a less marked difference between median rankings of glycated haemoglobin and of glycaemia than when classified by $2 \mathrm{hBG}$, but the difference was still apparent (Table 1, Fig.2a). Eighteen of 20 high glycators and 16 of 22 low glycators remain in the same categories when classified by FBG.

\section{Blood-glucose profiles in high and low glycators}

Sixteen subjects (nine high and seven low glycators) satisfactorily completed this part of the study on two occasions (Table 2), and these did not differ from the non-participants in age, gender or body mass index ( $p>0.3$ for all comparisons). There was a significant correlation between mean blood-glucose on the two profiles and the mean value for $2 \mathrm{hBG}$ on the two GTTs $(r=0.63, p<0.01$, $n=16$ ). The centile rankings of mean blood-glucose levels on the two profiles were calculated, and high and low glycators are compared in Table 2 and Figure $2 \mathrm{~b}$. High and low glycators show the same discrepancy of centile rank of mean blood-glucose as with $2 \mathrm{hBG}$, and there is no reclassification of subjects across the line of unity.

\section{Stability of levels of glycated haemoglobin}

Because a period of approximately four years had elapsed between the original screening study and the blood-glucose profile study, the levels of glycated haemoglobin were re-estimated by the same assay methods in seven high and six low glycators. Only three of the 13 subjects had changed category as a result of reclassification by the repeat assays of glycated haemoglobin, including one low glycator who had developed diabetes in the interim period. The differences in centile ranking between mean glycated haemoglobin centiles on repeat assay and mean $2 \mathrm{~h}$ blood-glucose centiles, calculated as in Table 2, remained 

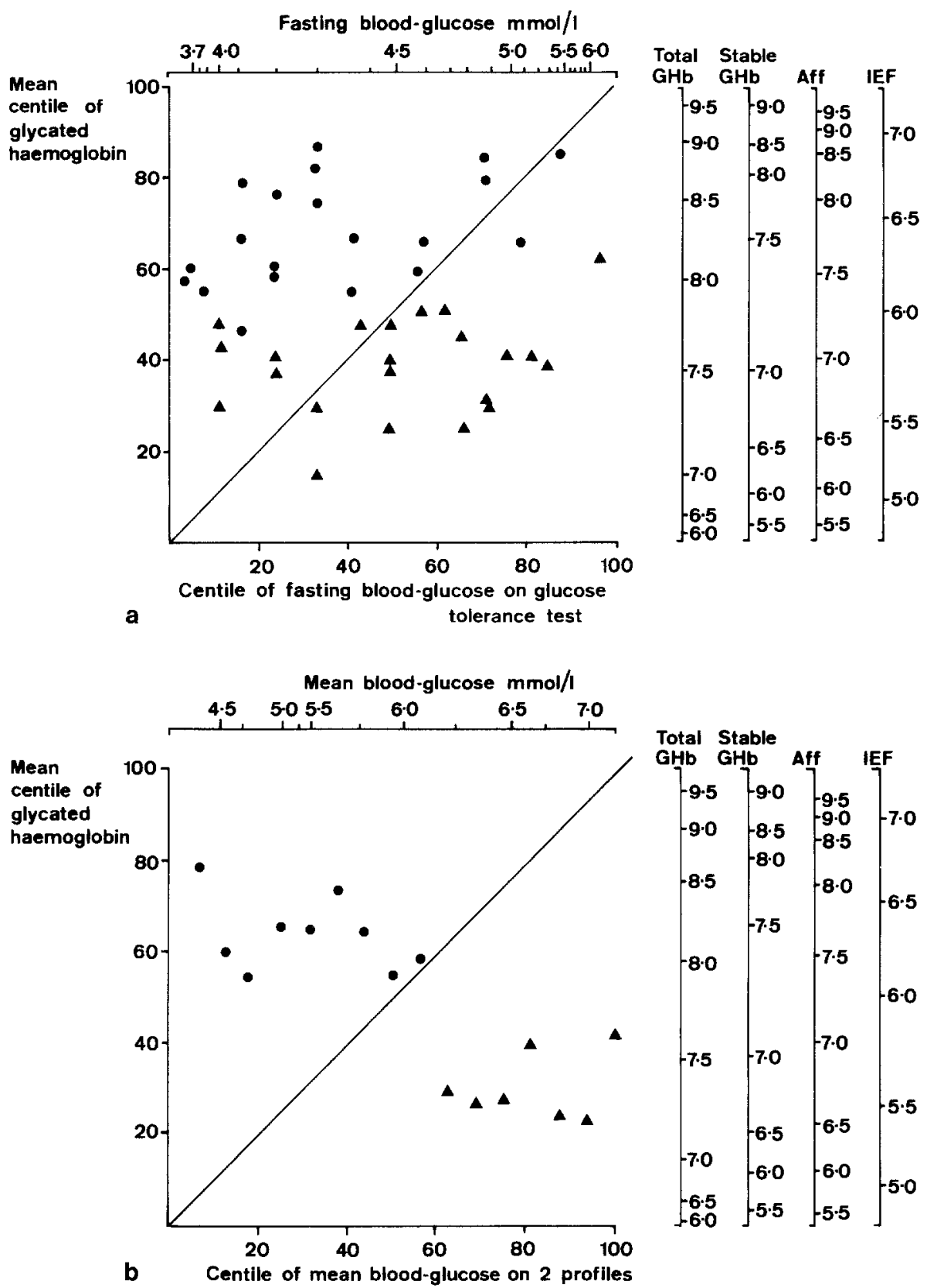

Fig. 2 a and b. Mean centile rankings of blood-glucose and of all assays of glycated haemoglobin in high and low glycators. a Centile rankings of fasting blood-glucose and mean centile rankings of all assays of glycated haemoglobin at screening and recall. The line of agreement is indicated. b Centile rankings of mean blood-glucose levels and mean centile rankings of all assays of glycated haemoglobin at screening and recall in 16 subjects completing ambient blood-glucose profile. The line of agreement is indicated. High glycators are represented as $\bullet$ and low glycators as $\boldsymbol{\Delta}$. The corresponding levels of blood-glucose, and of $2 \mathrm{~h}$ post-load assays of glycated haemoglobin are indicated. Abbreviations as for Figure 1

highly significant in high and low glycators $(t=3.74,11 \mathrm{df}$, $p<0.003$ ). There was also a significant difference in centile ranking between repeat assay mean glycated haemoglobin centile and mean profile blood-glucose centile $(t=3.55,11 \mathrm{df}, p<0.005)$.

\section{Dietary survey}

Twelve of the 20 high glycators and 13 of the 22 low glycators satisfactorily completed the dietary survey. There was no difference in age or gender between those who participated and the non-participants, but the latter were more obese $(p<0.02)$. There was no significant difference in the intake of total carbohydrates, sugars, glucose equivalents, total or soluble fibre, or vitamins $\mathrm{B} 6$ or $\mathrm{C}$ between high and low glycators. Moreover, no significant differen-

ces were found when nutrient intake was expressed as a proportion of total energy intake or as a percentage of body weight. These results were unaffected by excluding the four subjects reporting a change in dietary patterns during the period between the screening survey and the dietary survey.

\section{Discussion}

We have demonstrated wide inter-individual differences in the degree of haemoglobin glycation relative to the levels of fasting and post-load blood-glucose in a population comprising predominantly non-diabetic subjects, such that only around one quarter to one third of the variance of glycated haemoglobin can be explained on the basis of these measures of glucose intolerance. The weak 
relationship is not random, as the levels of glycated haemoglobin relative to glucose intolerance remained constant over 4.4 years. We have analysed possible determinants of consistently high and low levels of glycated haemoglobin but have not identified differences in ambient blood-glucose levels or in diet. While the high and low glycators investigated in this study were a highly selected subgroup, they did not differ significantly from the total study population other than in their levels of glycated haemoglobin. Nevertheless, the stratification of the screened population for selecting subjects for recall will have resulted in over-representation of both high and low glycators in the recall population.

We found that glycated haemoglobin assay imprecision and the variability of the glucose tolerance test [3133] were not the major determinants of the poor relationship. Glycated haemoglobin levels measured by all assay methods showed a considerable range in our study sample [14], probably as a result of the heterogeneity of the population, for example in terms of age, ethnic origin and social class, and thus high and low glycators may demonstrate differences of levels of glycated haemoglobin of $1-2 \%$ at the same degree of glucose intolerance (Fig. 1). The major determinant of glycated haemoglobin levels in Type 2 (non-insulin-dependent) diabetic subjects is the fasting blood-glucose concentration [21], but employing this measure of glycaemia rather than $2 \mathrm{hBG}$ did not explain differences in levels of glycated haemoglobin between high and low glycators. While the five-point blood-glucose profiles employed in the study may not accurately reflect ambient blood-glucose levels, the mean levels on the two profiles differed significantly between high and low glycators, suggesting that these observed differences in glycation are not thereby explained. There is no systematic gender difference in glycated haemoglobin [34], a difference which some previous studies have suggested $[35,36]$.

Our results imply that in non-diabetic subjects factors other than the degree of glucose intolerance may contribute as much as one third to one half the proportion of the variance of the glycated haemoglobin level contributed by glycaemia per se. In diabetic patients, the previously reported correlations of as much as 0.98 between levels of glycated haemoglobin and of mean blood-glucose [5] may result from the higher levels of ambient blood-glucose disguising any such contribution. In population studies, the correlation coefficients are much weaker than those found in diabetic patients because of the narrower range of the levels of the variables, and they may even be insignificant in non-diabetic subjects [6-9, 37, 38].

Three previous studies have produced findings consistent with our own. One has investigated the relationship between levels of glycated haemoglobin and measures of glycaemia on glucose tolerance testing in subjects with normal glucose tolerance [39] and also reported wide differences in these levels which were poorly explained by fasting or $2 \mathrm{hBG}$, and which remained stable over a period of more than 3 years. That study employed only a single ion exchange chromatography method for assay of glycated haemoglobin, so it is possible that other modifications of the haemoglobin molecule may be in part responsible for their findings. The boronate affinity chromatography method employed in our study separates only haemoglobin molecules with cis-diol sugar residues attached to them [40], and for this reason it is unlikely that other modifications of the haemoglobin molecule, such as occur in uraemia [41], during treatment with salicylates [42], or with abnormal haemoglobins [43], were responsible for our findings. In a study of six pregnant Type 1 (insulin-dependent) diabetic subjects, Madsen et al. [44] found good correlation between $\mathrm{HbA}_{1 \mathrm{c}}$ concentrations and blood-glucose levels in the previous eight weeks as determined by reflectance meter; however, the intercepts of the regression lines for these subjects differed substantially, so that any level of glycated haemoglobin might correspond to mean blood-glucose levels as much as $4 \mathrm{mmol} / \mathrm{l}$ apart. The authors provided no information in this study of the accuracy of reflectance meter readings of blood-glucose. Finally, a recent study examined levels of post-load blood-glucose and of glycated haemoglobin in 129 men and showed that $22 \%$ had discordant elevation of one or other value to a level above the 97.5 centile of a normal population [45]. Most of the group of subjects with abnormalities of glucose tolerance but normal glycated haemoglobin levels would probably be defined as having impaired glucose tolerance (IGT) by WHO criteria [30], and most previous studies have reported normal levels of glycated haemoglobin in subjects with IGT $[6-8,46]$. The study did not look further at the determinants of the discordant elevations, and, because both the glucose tolerance test and the glycated haemoglobin assay were performed on a single occasion, the problems of assay and biological variability remain. In our study $50 \%$ of the low glycators had IGT.

Ambient or fasting blood-glucose levels may in certain circumstances alter in different directions from those of the response to a glucose load. Thus, starvation and carbohydrate-restriction cause glucose intolerance [47] with lowering of glycated haemoglobin [48], and a high carbohydrate intake may improve glucose tolerance [49] while elevating postprandial blood-glucose levels [50]. We found no evidence for differences in carbohydrate or fibre intake between high and low glycators. Vitamin B 6 and C may affect glycation $[51,52]$ but intake did not differ between the groups. Modan et al. [39] did not find any contribution of dietary intake to glycated haemoglobin levels in subjects with normal glucose tolerance. It should be noted that the small size of the dietary study means that the calculated confidence interval for the true difference of intake between groups is wide. Moreover, the diet history has been criticised as not reflecting the wide variability of daily nutrient intake $[53,54]$. However, in this elderly population we have found a much smaller variability of measures of sodium intake than previously reported [55], suggesting that in such a population a seven day dietary history may be a valuable tool.

The consistent levels of glycated haemoglobin by assays employing different physicochemical properties implies that other chemical alterations of haemoglobin [39, 40] are unlikely to be responsible for high levels. Modan et al. [39] have shown higher levels of glycated haemoglobin in smokers than non-smokers, a finding which in our study 
just failed to reach significance. Other mechanisms, unrelated to mean blood-glucose levels, including erythrocyte survival and levels of competing molecules, such as amino acids or 2.3 diphosphoglycerate, may be responsible for the existence of high and low glycators and we are currently exploring these possibilities.

In conclusion, we have found marked differences in individual levels of glycated haemoglobin, relative to fasting, $2 \mathrm{~h}$, or ambient blood glucose, in a population of subjects without known diabetes, which remain consistent during a period of over four years, and have been unable to find differences in blood-glucose levels or dietary patterns to explain them. These findings may be of importance in the interpretation of levels of glycated haemoglobin, especially in screening programmes and in pregnancy where most levels are likely to be close to the normal range.

Acknowledgements. We are grateful to the general practitioners at the St. John's Way Medical Centre, London N19, UK for permission to study their patients, and to the staff at the Centre for their unstinting help. We thank Mrs. M. Casburn-Budd for her assistance with some of the glycated haemoglobin assays and Dr. B. Newman, Department of Statistical Sciences, University College London, for statistical advice. Data contained in this report is included as part of RDF's MD Thesis of the University of London. The Islington Diabetes Survey was supported by the Wellcome Trust, RDF by the North East Thames RHA Locally Organised Research Scheme, and SD by the Medical Research Council. Beecham Products plc generously supplied the Lucozade for the glucose tolerance tests, and Servier Laboratories Ltd provided additional financial support.

\section{References}

1. Kennedy L, Baynes JW (1984) Nonenzymatic glycosylation and the chronic complications of diabetes: an overview. Diabetologia 26: $93-98$

2. Brownlee M, Vlassara H, Cerami A (1984) Nonenzymatic glycosylation and the pathogenesis of diabetic complications. Ann Int Med 101:527-537

3. Editorial (1986) Browning and diabetic complications. Lancet I: 1192-1193

4. Koenig RJ, Peterson CM, Jones RL, Saudek C, Lehrman M, Cerami A (1976) Correlation of glucose regulation and hemoglobin $A_{1 c}$ in diabetes mellitus. NEngl J Med 295: 417-420

5. Svendsen PA, Lauritzen T, Soegaard U, Nerup J (1982) Glycosylated haemoglobin and steady-state mean blood glucose concentration in Type 1 (insulin-dependent) diabetes. Diabetologia 23: 403-405

6. Boucher BJ, Welch SG, Beer MS (1981) Glycosylated haemoglobins in the diagnosis of diabetes mellitus and for the assessment of chronic hyperglycaemia. Diabetologia 21:34-36

7. John WG, Richardson RW (1986) Glycosylated haemoglobin levels in patients referred for oral glucose tolerance tests. Diab Med 3: 46-48

8. Lev-Ran A, VanderLaan WP (1979) Glycohemoglobins and glucose tolerance. JAMA 241:912-914

9. Simon D, Coignet MC, Thibult N, Senan C, Eschwege E (1985) Comparison of glycosylated hemoglobin and fasting plasma glucose with two-hour post-load plasma glucose in the detection of diabetes mellitus. Am J Epidemiol 122: 589-593

10. Forrest RD, Jackson CA, Yudkin JS (1986) Glucose intolerance and hypertension in North London. The Islington Diabetes Survey. Diab Med 3: 338-342
11. Forrest RD, Jackson CA, Yudkin JS (1987) The glycohaemoglobin assay as a screening test for diabetes mellitus. The Islington Diabetes Survey. Diab Med 4: 254-259

12. Forrest RD (1987) Screening for diabetes mellitus. Evaluation of glycohaemoglobin assays as screening tests. The Islington Diabetes Survey. MD Thesis, University of London, pp 254

13. Forrest RD, Jackson CA, Casburn-Budd M, Taylor JE, Gould BJ, Yudkin JS (1987) Short term effect of 75 g oral glucose on glycohaemoglobin levels. Ann Clin Biochem 24:53-57

14. Forrest RD, Jackson CA, Gould BJ, Casburn-Budd M, Taylor JE, Yudkin JS (1988) Four assays of glycated hemoglobin compared as screening tests for diabetes mellitus: the Islington Diabetes Survey. Clin Chem 34: 145-148

15. Holdsworth MD, Davies L, Wilson A (1984) Simultaneous use of four methods of estimating food consumption. Hum Nutr: Appl Nutr 38A: 132-137

16. Paul AA, Southgate DAT (1978) McCance and Widdowson's The composition of foods, 4 th edn. HMSO, London, pp 418

17. Southgate DAT, Paul AA, Dean AC, Christie AA (1978) Free sugars in foods. J Hum Nutr 32: 335-347

18. Englyst HN, Cummings JH (1984) Simplified method for the measurement of total non-starch polysaccharides by gas-liquid chromatography of constituent sugars as alditol acetates. Analyst 109: 937-942

19. Englyst HN, Bingham SA, Runswick SA, Collinson E, Cummings JH (1988) Dietary fibre (non-starch polysaccharides) in fruit, vegetables and nuts. J Human Nutr Dietetics 1:247-286

20. Holman RR, Turner RC (1980) The basal plasma glucose: a simple relevant index of maturity-onset diabetes. Clin Endocrinol 14:279-286

21. Paisey RB, Bradshaw P, Hartog M (1980) Home blood glucose concentrations in maturity-onset diabetes. Br Med J 280: 596-598

22. Pecoraro RE, Koepsell TD, Chen MS, Lipsky BA, Belcher DW, Inui TS (1986) Comparative clinical reliability of fasting plasma glucose and glycosylated hemoglobin in non-insulin-dependent diabetes mellitus. Diabetes Care 9: 365-369

23. Burrin JM, Price CP (1984) Performance of three enzymic methods for filter paper glucose determination. Ann Clin Biochem 21: $411-416$

24. Menard L, Dempsey ME, Blankstein LA, Aleyassine H, Wacks M, Soeldner JS (1980) Quantitative determination of glycosylated hemoglobin $\mathrm{A}_{1}$ by agar gel electrophoresis. Clin Chem 26: 1598-1602

25. Nathan DM, Dunn BS, Francis TB (1984) Two commercial methods evaluated for eliminating the labile fraction from the assay for glycated hemoglobin (glycohemoglobin). Clin Chem 30: $109-110$

26. Gould BJ, Hall PM, Cook JGH (1982) Measurement of glycosylated haemoglobins using an affinity chromatography method. Clin Chim Acta 25: 41-48

27. Mortensen HB (1980) Quantitative determination of hemoglobin $\mathrm{A}_{1 \mathrm{c}}$ by thin layer iso-electric focusing. J Chromatog 182: 325-333

28. Little RR, England JD, Weidmeyer H-M, Goldstein DE (1983) Effects of whole blood storage on results for glycosylated hemo-

globin as measured by ion-exchange chromatography, affinity chromatography and colorimetry. Clin Chem 29:1113-1115

29. Forrest RD, Jackson CA, Yudkin JS (1987) The epidemiology of the haemoglobin level - a study of 1057 subjects in general practice. Postgrad Med J 63: 625-628

30. World Health Organisation Study Group on Diabetes Mellitus (1985) A Report of a WHO Study Group. Technical Report Series, No 727, WHO, Geneva

31. Forrest RD, Jackson CA, Yudkin JS (1988) The abbreviated glucose tolerance test in screening for diabetes: the Islington Diabetes Survey. Diab Med 5: 557-561

32. McDonald GW, Fisher GF, Burnham C (1965) Reproducibility of the oral glucose tolerance test. Diabetes 14: 473-480

33. Riccardi G, Vaccaro O, Rivellese A, Pignalosa S, Tutino L, Mancini M (1985) Reproducibility of the new diagnostic criteria for impaired glucose tolerance. Am J Epidemiol 121: 422-429 
34. Forrest RD, Jackson CA, Yudkin JS (1987) Glucose tolerance and glycohaemoglobin; a population study of male-to-female ratios. Diab Med 4: 322-324

35. Stickland MH, Paton RC, Wales JK (1984) Haemoglobin $\mathrm{A}_{1 \mathrm{c}}$ concentrations in men and women with diabetes. Br Med J 289: 733

36. Jones RB, Johnston DI, Allison SP, Peacock I, Hosking DJ, Tattersall RB (1984) Haemoglobin $A_{1 c}$ concentrations in men and women with diabetes (Letter). Br Med J 289: 1381

37. Dix D, Cohen P, Kingsley S, Senkbeil J, Sexton K (1979) Glycohemoglobin and glucose tolerance tests compared as indicators of borderline diabetes. Clin Chem 25: 877-879

38. Dods RF, Bolmey C (1979) Glycosylated hemoglobin assay and oral glucose tolerance test compared for detection of diabetes mellitus. Clin Chem 25: 764-768

39. Modan M, Meytes D, Rozeman P, Yosef SB, Sehayek E, Yosef NB, Lusky A, Halkin H (1988) Significance of high $\mathrm{HbA}_{1}$ level in normal glucose tolerance. Diabetes Care 11: 422-428

40. Gould BJ, Hall PM (1987) m-Aminophenylboronate affinity ligands distinguish between nonenzymically glycosylated proteins and glycoproteins, Clin Chim Acta 163: 225-230

41. Flückiger R, Harman W, Meier W, Loo S, Gabbay KH (1981) Hemoglobin carbamylation in uremia. $\mathrm{N}$ Engl $\mathrm{J}$ Med 304: 823-827

42. Bridges KR, Schmidt GJ, Jensen M, Cerami A, Bunn HF (1975) The acetylation of hemoglobin by aspirin in vitro and in vivo. J Clin Invest 56: 201-207

43. Eberentz-Lhomme C, Ducrocq R, Intrator S, Elion J, Nunez E, Assan R (1984) Haemoglobinopathies: a pitfall in the assessment of glycosylated haemoglobin by ion-exchange chromatography. Diabetologia 27:596-598

44. Madsen H, Ditzel J, Hansen P, Hahnemann N, Andersen OP, Kjaergaard $J_{-} J$ (1981) Hemoglobin $A_{1 c}$ determinations in diabetic pregnancy. Diabetes Care 4: 541-546

45. Starkman HS, Soeldner JS, Gleason RE (1987) Oral glucose tolerance: relationship with haemoglobin $\mathrm{A}_{\mathrm{Ic}}$. Diab Res Clin Pract 3: 343-349

46. Albutt EC, Nattrass M, Northam BE (1985) Glucose tolerance test and glycosylated haemoglobin measurement for diagnosis of diabetes mellitus - an assessment of the criteria of the WHO Expert Committee on Diabetes Mellitus. Ann Clin Biochem 22: 67-73
47. Wilkerson HLC, Hyman H, Kaufman M, McCuistion AC, Francis JO'S (1960) Diagnostic evaluation of oral glucose tolerance tests in nondiabetic subjects after various levels of carbohydrate intake. N Engl J Med 262: 1047-1053

48. Ktorza P, Baigts F, Fumeron F, Rizkalla S, Kinebanyan FM (1985) Effects of slight plasma glucose decrease on glycosylated hemoglobin in healthy subjects during caloric restriction (letter). N Engl J Med 313: 958-959

49. Brunzell JD, Lerner RI, Hazzard WR, Porte D, Bierman EL (1971) Improved glucose tolerance with high carbohydrate feeding in mild diabetes. N Engl J Med 284: 521-524

50. Simpson RW, Mann JI, Eaton J, Moore RA, Carter R, Hockaday TDR (1979) Improved glucose control in maturity-onset diabetes treated with high-carbohydrate-modified fat diet. $\mathrm{Br}$ Med J 1: $1753-1756$

51. Shepard DC, Hitz JB, Dain JA (1985) Pyridoxal 5'-phosphate inhibits nonenzymatic glycosylation of proteins. Biochem Arch 1: $143-151$

52. Štolba P, Hátle K, Krnáková A, Strěda M, Stárka L (1987) Effects of ascorbic acid on nonenzymatic glycation of serum proteins in vitro and in vivo. Diabetologia 30:585 (Abstract)

53. Burke BS (1947) The dietary history as a tool in research. J Am Diet Assn 23: 1041-1046

54. James WPT, Bingham SA, Cole TJ (1980) Epidemiological assessment of dietary intake. Nutr Cancer 2: 203-212

55. Elliott P, Forrest RD, Jackson CA, Yudkin JS (1988) Sodium and blood pressure: positive associations in a North London population with consideration of the methodological problems of within-population surveys. J Hum Hypertens 2: 89 95

Received: 16 June 1989

and in revised form: 31 October 1989

Dr. J.S. Yudkin

Academic Unit of Diabetes and Endocrinology

Whittington Hospital

Archway Road

London N195NF

UK 